\title{
Effects of spacing and embellishment on memory for the main points of a text
}

\author{
LYNNE M. REDER and JOHN R. ANDERSON \\ Carnegie-Mellon University, Pittsburgh, Pennsylvania 15213
}

\begin{abstract}
An advantage has been found for acquiring textbook knowledge by studying textbook summaries rather than reading the original prose (Reder \& Anderson, 1980). Three studies are presented that help to establish the cause of the summary advantage. One possible cause is that reading summaries allows the subject to reread the main points at spaced intervals, and spaced practice is superior to massed practice. A second possible cause is that the presence of details distracts the subject's attention away from the critical ideas that should be attended to. In Reder and Anderson (1980), these two factors were confounded, but they are unconfounded in the present studies. The results indicate that both possible causes, spaced practice and the absence of details, have significant, independent, and positive effects on retention of the central ideas of a passage.
\end{abstract}

This research is concerned with understanding some of the effects of details in a typical textbook format on learning from such a text. When one considers that college textbooks are hundreds of pages long and contain tens of thousands of facts, one cannot seriously expect a college student to master all the facts on all the pages. Given that mastery of all the ideas is not expected, what are students intended to learn and why are so many details included in the text?

Texts are intended to communicate a set of skills for reasoning and thinking cogently within the field. They include a large number of details to support the central ideas of the book. These details acquaint the student with the argument structure of the field. They may also persuade the student to believe the claims the text is making.

These potential functions of details do not address the issue of whether details support memory for the main points of a text. An important question is whether the inclusion of details is justified on the grounds of helping to retain the main points. One argument is that embellishments allow the reconstruction of the main points. Details imply the main points, although the converse is not true. The details, then, could allow the student to induce a central idea when it has been forgotten.

There are alternative arguments that can be made for why details should not support memory for the important ideas. Cognitive scientists (e.g., Crothers, 1972; Frederiksen, 1975; Kintsch, 1974; Kintsch \&

This research was supported by ONR Contract N00014-78C.0725. Correspondence concerning this paper should be sent to Lynne M. Reder, Department of Psychology, Carnegie-Mellon University, Pittsburgh, Pennsylvania 15213. We wish to thank B. Adams, L. Hyatt, and L. Kronick for assistance in material construction and data collection. van Dijk, 1975; Mandler \& Johnson, 1977; Meyer, 1975; Rumelhart, 1975; Stein \& Glenn, 1977; Thorndyke, 1977) have proposed theories of the structure of text that involve hierarchical representations of the idea units in the text, with the more important propositions represented higher in the hierarchy. The predominant notion is that one can access details only if one has first accessed the higher order ideas that subsume them. Thus, memory for main points is supposed to support memory for details, and not the converse. Indeed, investigations of these representations have found that propositions higher and more central in these hierarchies are better recalled, more accurately recognized, and more rapidly verified (e.g., Kintsch, 1974; Kintsch \& van Dijk, 1975; Meyer, 1975). Of course, none of these results in and of themselves imply that details do not support memory for the main points.

A recent paper by Reder and Anderson (1980) investigated whether or not details benefit memory for the main points of a passage. Subjects read one passage in the original text form and a second passage in a summarized form. The summary form sacrificed all the redundancy and embellishments that come from the inclusion of details. The summaries were devised to retain the main points of the chapter, but not to save the paragraph style. One unembellished fact was listed per line.

To our surprise, all seven experiments indicated that subjects learn information better when they read an abridged or summarized version of the original text than when they read the original chapter. The advantages for summaries were maintained at retention intervals of $20 \mathrm{~min}, 1$ week, and 6-12 months. Summaries were superior both for questions that directly tested assertions from the text and for inferences that required the subject to combine facts that had been studied. Subjects also learned new, related material better (regardless of 
input form) when prior information had been learned in summary form. The retention advantage was also manifested in reaction times, such that subjects answered questions faster (and also more confidently) when they had read the summaries. Even when the main points in the text were underlined, subjects performed better with summaries.

The purpose of this investigation is to try to determine the cause of the summary advantage. Two hypotheses occurred to us: (1) Summaries allow subjects to focus more attention on the relevant or important information than is possible when they must assimilate all the information in a text. (2) The summaries have the advantage of spaced study, whereas the text has massed study.

Rather than focusing on each main point in the summary for a long time, a subject can cycle through each main point several times at spaced intervals. In contrast, the prose can be thought of as consisting of one main point followed by its embellishing ideas, then a second main point and its corresponding details, and so on. Because there is more information to read, a subject will probably be able to read the prose version only once in the allotted time. (Most of the earlier experiments equated study time in the two conditions. However, performance was superior in the summary condition even when the prose condition was allotted three times as much study time.)

The first argument, the focus-of-attention argument, is supported by related studies in the reading literature (Frase, 1967, 1968, 1971, 1972, 1975; Rothkopf, 1966, 1972; Rothkopf \& Bisbicos, 1967; Watts \& Anderson, 1971). In general, these studies have shown that people perform better on criterion tests of text comprehension if they have previously been given orienting instructions or priming questions regarding the text. The summaries could be viewed as an extreme version of how to focus attention.

The second argument, the spacing-of-study-time view, is supported by a large body of verbal learning literature that shows that, for a given amount of study or rehearsal time, subjects remember much more when that study time is distributed than when it is massed (e.g., Gartman \& Johnson, 1972; Glenberg, 1976; Hintzman, 1969; Madigan, 1969; Melton, 1970). One can view the prose version as forcing subjects into massed practice, namely, to pay attention to one idea (a main point and its embellishments) for a long time, thereby having too little time to return to that idea later.

Our previous studies did not allow us to pull apart these two possible explanations for the summary superiority. Conceivably, only the absence of details caused the advantage for summaries; possibly only the spacing of practice caused the advantage, or perhaps both factors have an effect on learning and retention.

The present set of experiments was designed to pull apart these two potential causes. This required going to a less "naturalistic" task. In the previous experiments, the prose condition allowed subjects to read, at their own pace, photocopies of the original textbook passages. The summaries were also read at a subject's own pace. In the present experiments, subjects read all material on a computer-controlled video monitor. We orthogonally varied whether subjects studied embellishments with the main points and whether the equivalent study time was massed into one trial or distributed over three trials. The embellished, "massed" condition most closely approximates the normal prose condition; the unembellished, spaced condition resembles the summary condition.

\section{EXPERIMENT 1}

\section{Method}

Four topics were selected for subjects to study. Subjects studied one topic in each of the four conditions: embellishedmassed, embellished-spaced, unembellished-massed, and unembellished-spaced. In the embellished-massed condition, a main point plus three details were presented on the screen at one time. These were displayed for a total of $42 \mathrm{sec}$ before the screen was erased and a new set of facts was presented. In the embellished-spaced condition, subjects saw one main point plus one detail on the screen at a given time. The fact and detail were presented for $14 \mathrm{sec}$ of study. Then the screen was erased and a different main point and embellishment were presented on the screen for study. The program cycled through all the main points in this manner. Then it went through the main points a second and a third cycle, each cycle with a different embellishment. In the unembellished-massed condition, a point was presented only once, but for $42 \mathrm{sec}$. In the unembellishedspaced condition, a main point was presented in isolation on the screen for $14 \mathrm{sec}$ and then was replaced by another fact. After all main points had been presented, the screen cycled through the same main points again for a second time, and then a third time.

Order of presentation of the four topics for study was randomly determined, as was assignment of topics to conditions, under the constraint that the assignment of topics to conditions and order of conditions was counterbalanced over subjects. After subjects completed studying one topic, they were asked questions about the material. After studying all four topics, they were asked more questions about each topic, in the order that they had studied those topics. This second set of tests is referred to as delayed testing. The questions were all true-false. Latencies were surreptitiously recorded (in seconds) from the onset of the question until the response. The primary dependent measure was accuracy. Feedback concerning accuracy was not given.

Materials. Four topics were chosen from introductory texts in four different fields: photography (Introduction to Photography by Rhode \& McCall, 1971), ecology (Ecology and the Quality of Our Environment by Southwick, 1972), African economic geography (The Geography of Modern Africa by Hance, 1975), and Russian revolutionary history (Russia: $A$ Short History by Florinsky, 1969). For each topic, 32 main or central points were isolated for each chapter, with three embellishments per point. Both the main points and the embellishments were from the original text. Only minor changes in wording of any sentence were necessary. Thirty-two true-false questions were constructed to tap comprehension of each main point. Care was taken so that no true-false questions were answered much above or below chance accuracy $(50 \%)$ by subjects who had not studied the material. Pilot subjects screened our materials. Any questions answered significantly above or below chance were replaced by other questions that were also 
checked. Examples of some main points, their embellishments, and their true-false questions are given in the appendix.

Subjects. Thirty-two subjects participated in the experiment in partial fulfillment of a requirement for their psychology course. The experiment took approximately $2 \mathrm{~h}$, and subjects received two of the required three credits. A design that balanced four topics, four conditions, and four presentation orders required 16 subjects. So there were two subjects per design instantiation.

\section{Results}

Table 1 presents the accuracy and latency results of Experiment 1. The data come from eight conditions that are all combinations of the factors immediate vs. delayed test, spaced vs. massed practice, and embellished vs. unembellished main points. The latencies are mean time to answer all questions, whether the answers were correct or not, truncated at $20 \mathrm{sec}^{1}$ We are simply using these times as a gauge of the difficulty of a condition. An analysis of variance was performed on the accuracy data using the above factors and treating the Subject by Factor interactions as the error terms for each factor. A separate analysis using the same factors was performed on the latency data.

Consider first the accuracy data in the immediate conditions. There was an advantage for spaced practice and an advantage for unembellished presentation of the main points. In the delayed condition, neither effect was maintained. At delay, spacedembellished was better than massed-embellished and massed-unembellished was a more accurate condition than massed-embellished, but there appeared to be one aberrant cell, namely, the unembellished-spaced condition. If the value in that cell had been elevated, there might have been more statistically significant effects. Only the effect of embellishment was reliable overall $[\mathrm{F}(1,31)=7.36, \mathrm{MSe}=.007$, $p<.02]$, such that subjects were still better off learning without details. The effect of spacing was not significant $[F(1,31)=.69, \mathrm{MSe}=.05, \mathrm{p}>.4]$. The size of the embellishment effect was $2.7 \%$. The spaced-massed difference was $2.3 \%$. The reason the former was significant and the latter was not is due to the large difference in their respective mean square errors. There was a marginally significant triple interaction of embellishment, spacing, and delay $[\mathrm{F}(1,31)=3.56, \mathrm{MSe}=.014, \mathrm{p}<.07]$. The latter effect was probably spurious, due to the especially low cell mentioned above.

We were surprised not to find a significant effect of spacing, as one finds in most learning situations.
However, for several reasons, we did not abandon the notion that spacing would have an effect. One reason was the latency data, also displayed in Table 1. Subjects were significantly faster to judge probes when the rele. vant information had been studied in spaced rather than in massed form $[\mathrm{F}(1,31)=10.17, \mathrm{MSe}=2.18, \mathrm{p}<.01]$. So, rather than large differences in accuracy, the advantage of spacing was manifested in latencies to respond to the questions. There were no other significant effects on the latency measures.

The second reason that we felt the experiment may not have indicated as strong a role of spaced practice as was warranted was due to the nature of our dependent measure. True-false questions may not have been sensitive enough to accurately reflect learning differences. Others have found that spacing effects are weaker in a recognition task than in a recall task (e.g., Glenberg, 1976; Ross \& Landauer, 1978). To discover whether the small effects were due to the nature of the criterion task, we decided to replicate Experiment 1 using a more sensitive retention test.

\section{EXPERIMENT 2}

In this experiment, our dependent measure was accuracy of answers to probe recall questions rather than true-false questions. The questions tended to be "wh" questions (e.g., "What keeps solutions uniform, thereby avoiding streaks on the negatives?" and "To whom did the Emperor abdicate?"). We thought that this might provide a more sensitive measure of differences in learning than did the true-false questions; with greater variance in the means, we hoped to see strong effects of our manipulations. In all other respects, the second experiment was a replication of the first.
Method
Again, there were four topics and four conditions, the same as those used in Experiment 1 . Presentation order of topics and assignment of topics to conditions were randomly determined for each subject, using the same constraints as had been used for counterbalancing in Experiment 1 . The material was again pre- sented on a computer-controlled video terminal. Half of the questions were asked after the subjects had studied each passage. The remaining questions for all topics were asked after all four topics had been studied. Subjects were not given feedback as to the accuracy of their responses. The experiment took between 2 and $3 \mathrm{~h}$ to complete.
Materials. Each of the four topics, ecology, geography, photography, and Russian history, had 32 main points. For each

Table 1

Mean Proportion Correct (P) and Latency (L) in Seconds as a Function of Spacing, Embellishment, and Delay in Experiment 1

\begin{tabular}{|c|c|c|c|c|c|c|c|c|}
\hline & \multicolumn{4}{|c|}{ Immediate } & \multicolumn{4}{|c|}{ Delayed } \\
\hline & \multicolumn{2}{|c|}{ Spaced } & \multicolumn{2}{|c|}{ Massed } & \multicolumn{2}{|c|}{ Spaced } & \multicolumn{2}{|c|}{ Massed } \\
\hline & $\mathbf{P}$ & $\mathrm{L}$ & $\mathbf{P}$ & $\mathbf{L}$ & $\mathbf{P}$ & $\mathbf{L}$ & $\mathbf{P}$ & L \\
\hline Embellished & .697 & 6.78 & .680 & 7.73 & .719 & 5.60 & .650 & 6.14 \\
\hline Unembellished & .750 & 6.84 & .715 & 7.30 & .681 & 5.68 & .709 & 6.09 \\
\hline
\end{tabular}


main point, one question was constructed. Typically, the subject (focus) of the sentence or some part of the predicate was deleted and the sentence was transformed into question format. The appendix gives some examples of questions used.

Subjects. Thirty-two subjects participated in the experiment, so that we had two subjects per cell instantiation of the counterbalancing design. The experiment took $2.5 \mathrm{~h}$. Subjects received either two credits and $\$ 2$ or one credit and $\$ 5$.

\section{Results}

Table 2 presents the accuracy data for Experiment 2 for the eight conditions (four conditions times two levels of delay). In this experiment, response times were not recorded, since subjects had to type a phrase rather than select one of two keys. The scoring of the answers, of course, required some degree of subjectivity. A scorer was presented, by computer, the answers of all subjects to each question. The scorer rated each answer right or wrong. In that way, consistency in ratings could be maintained and the rater was blind to condition of response.

As before, there was a significant effect of embellishment $[F(1,31)=90.04$, MSe $=.015, p<.001]$ such that subjects were better off studying the material without the "aid" of supporting details. This time, however, there was also a main effect of spacing $[F(1,31)=21.51, \quad \mathrm{MSe}=.021, \mathrm{p}<.001]$ such that subjects answered questions more accurately if they had studied the topics with distributed (or spaced) rather than massed practice. There was also a main effect of delay $[F(1,31)=74.33, \mathrm{MSe}=.008, \mathrm{p}<.001]$; subjects remembered more immediately after studying the material than they did $1 \mathrm{~h}$ later.

There was also a significant interaction of spacing with delay $[F(1,31)=5.14, \mathrm{MSe}=.013, \mathrm{p}<.05]$. For some reason, the benefit of spacing decreased with delay. This contradicts results such as those of Glenberg (1976), by which benefit has been shown to increase with delay. However, in these other experiments, the short delay was on the order of a few seconds, not $30 \mathrm{~min}$. It is also worth noting that, in this experiment, unlike Experiment 1, the unembellished-spaced condition at delay was not an aberrant point with respect to the main effects of spacing and embellishment.

\section{Discussion}

Both experiments indicate that there is a clear advan. tage of presenting material in an unembellished form and that this result is independent of the spacing of study. In Experiment 1, using a recognition memory paradigm, this advantage was only 2.7\%; in Experiment 2, using a

Table 2

Mean Proportion Correct as a Function of Spacing, Embellishment, and Delay in Experiment 2

\begin{tabular}{lccccc}
\hline & \multicolumn{2}{c}{ Immediate } & & \multicolumn{2}{c}{ Delayed } \\
\cline { 3 - 5 } \cline { 5 - 6 } & Spaced & Massed & Spaced & Massed \\
\hline Embellished & .662 & .504 & .523 & .474 \\
Unembellished & .775 & .701 & .661 & .607 \\
\hline
\end{tabular}

recall measure, the size of this effect rose to $14.5 \%$. Both experiments indicated an independent advantage of spacing (2.3\% in Experiment 1 and $8.4 \%$ in Experiment 2). The percentage recognition measure in Experiment 1 was not significant, but there was a significant latency advantage for the spaced study condition. These results imply that in our previous experiments (Reder \& Anderson, 1980), in which embellishments and spacing were confounded, subjects were at a double advantage in the summary condition, receiving benefit of both spacing and lack of embellishment.

One implication of this research is that human memory should be considered a severely limited storage system. Providing a student with embellishments of a main point will take processing away from the main point and leave it at a disadvantage. The strong relationship that exists between the embellishment and the main point does little or nothing to promote memory for that main point.

One might wonder whether the disadvantage of the embellished conditions is due to the fact that there is less time to study the main points, or if the embellishments actually interfere with learning the main points. The results indicate that, for a fixed amount of study time, a person is better off spending that time learning just the main points; that is, embellishments actually hurt performance. It is possible, though, that if the study time for the main points were equated in the two conditions, embellishment would help retention, or at least not interfere. The motivation, then, for Experiment 3 was to see whether the advantage of the unembellished condition was due to more total study time for the main points or to the lack of interference of the details.

\section{EXPERIMENT 3}

All subjects studied the material in the spaced practice mode. All subjects studied the main points for the same amount of time. The independent variable in this study was only whether or not subjects saw the embellishments. To insure that the main points were studied for the same amount of time in both conditions, the main points were displayed on the screen in isolation in both conditions. The embellished condition had additional frames presented on the CRT screen, with a detail presented following the relevant main point. Rather than the subject's seeing a main point with one of its details for $14 \mathrm{sec}$, the main point was displayed by itself for $14 \mathrm{sec}$, followed by the detail displayed by itself for $14 \mathrm{sec}$. On the second presentation of the main point, the subsequent display was of the second detail; the third presentation was followed by the last detail.

\section{Method}

In this experiment, there were two conditions rather than four, because the two massed conditions were dropped. Therefore, two of the four topics were randomly assigned to condi- 
Table 3

Mean Proportion Correct as a Function of Embellishment and Delay in Experiment 3

\begin{tabular}{lcc} 
& Immediate & Delayed \\
\hline Embellished & .689 & .697 \\
Unembellished & .750 & .721 \\
\hline
\end{tabular}

tions for each subject; that is, across subjects, all four topics that were used in Experiments 1 and 2 were used in Experiment 3. Also, presentation order of topics and assignment of topics to conditions were randomly determined for each subject. The study material and testing material were presented on a computer-controlled video terminal. Again, half of the questions were asked after the subjects had studied each passage, and the remaining questions for both topics were asked after both had been studied. Subjects were not given feedback as to the accuracy of their responses. The experiment took about $2 \mathrm{~h}$ to complete. The embellished condition took twice as long as the unembellished condition, because study time for the main points was equated.

Materials. The materials were the same as those used in Experiments 1 and 2. The questions were the same as those in Experiment 2. The only difference was that only two of the four topics were used for any particular subject.

Subjects. Thirty-two subjects participated in this experiment, so that we had two subjects per cell instantiation of the counterbalancing design. Subjects received either two credits and $\$ 2.50$ or one credit and $\$ 5$.

\section{Results}

Table 3 presents the accuracy data for Experiment 3 for the four conditions (two conditions times two levels of delay). The data were scored in the same manner as in Experiment 2. The answers were presented by computer, and the scorer rated all answers to one question prior to judging the accuracy of another question. The scorer was unaware of the condition that generated a particular answer.

The data from two subjects were averaged together such that Subject A saw Topic 1 and Topic 2 in the embellished and unembellished conditions, respectively, and Subject B saw Topics 1 and 2 in the unembellished and embellished conditions, respectively. Moreover, this yoked pair of subjects saw the topics in the same order. This means that for a yoked pair, effects due to materials and effects due to presentation order of conditions were counterbalanced. An analysis of variance was performed on the 16 yoked subjects' data. Again, there was a significant effect of embellishment $[F(1,15)=5.60$, MSe $=.005, p<.05]$ such that subjects were better off studying the material without the details. There was no significant effect of delay. There was also no significant interaction of delay with the embellishment manipulation.

\section{GENERAL DISCUSSION}

We had initially expected that subjects would benefit from the details that are normally found in textbooks. We continue to be surprised at each study that supports the conclusion that details hurt retention of main points. We find it an important pedagogical point that details often hinder acquisition of central ideas. This has implications for the optimal use of study time. This last study indicates, to our surprise, that even when study time for main points is equated, there is no advantage for extra time spent on details. Not only is there no additional benefit of details, but details also hurt even when they are not competing for study time with the main points.

This set of experiments has argued that spaced practice of main points, and main points not hindered by details, improves the acquisition and retention of these central ideas. Quite probably, details do serve functions such as increasing interest and credibility. However, they also seem to have a cost in terms of hurting memory for the central ideas. That cost should be weighed carefully against those possible benefits.

\section{REFERENCES}

Crothers, E. J. Memory structure and the recall of discourse. In R. O. Freedle \& J. B. Carroll (Eds.), Language comprehension and the acquisition of knowledge. Washington, D.C: Winston, 1972.

Florinsky, M. P. Russia: A short history. London: Macmillan, 1969.

Frase, L. T. Learning from prose material: Length of passage, knowledge of results, and position of questions. Journal of Educational Psychology, 1967, 58, 266-272.

Frase, L. T. Questions as aids to reading: Some research and theory. American Educational Research Journal, 1968, 5, 319 332.

Frase, L. T. Effect of incentive variables and type of adjunct questions. Journal of Educational Psychology, 1971, 62, 371375.

Frase, L. T. Maintenance and control in the acquisition of knowledge from written materials. In R. O. Freedle \& J. B. Carroll (Eds.), Language comprehension and the acquisition of knowledge. Washington, D.C: Winston, 1972.

Frase, L. T. Prose processing. In G. H. Bower (Ed.), The psychology of learning and motivation (Vol. 9). New York: Academic Press, 1975.

FrEDERIKSEN, C. H. Representing logical and semantic structure of knowledge acquired from discourse. Cognitive Psychology, $1975,7,371-458$.

Gartman, L. M., \& Johnson, N. F. Massed versus distributed repetition of homographs: $A$ test of the differential-encoding hypotheses. Journal of Verbal Learning and Verbal Behavior, 1972, 11, 801-808.

Glenberg, A. M. Monotonic and nonmonotonic lag effects in paired-associate and recognition memory paradigms. Journal of Verbal Learning and Verbal Behavior, 1976, 15, 1-16.

HANCE, W. A. The geography of modern Africa. New York: Columbia University Press, 1975.

Hintzman, D. L. Apparent frequency as a function of frequency and the spacing of repetitions. Journal of Experimental Psychology, 1969, 80, 139-145.

KINTSCH, W. The representation of meaning in memory. Hillsdale, N.J: Erlbaum, 1974.

Kintsch, W., \& van DiJK, T. A. Comment on se rappelle et on resume des histoires. Languages, 1975, 40, 98-116.

Madigan, S. A. Intraserial repetition and coding processes in free recall. Journal of Verbal Learning and Verbal Behavior, $1969,8,828-835$. 
Mandler, J. M., \& Johnson, N. S. Remembrance of things parsed: Story structure and recall. Cognitive Psychology, 1977, 9, 111-151.

Melton, A. W. The situation with respect to the spacing of repetitions and memory. Journal of Verbal Learning and Verbal Behavior, 1970, 9, 596-605.

MEYER, B. J. F. The organization of prose and its effect on recall. Amsterdam: North-Holland, 1975.

Reder, L. M., \& Anderson, J. R. A comparison of texts and their summaries: Memorial consequences. Journal of Verbal Learning and Verbal Behavior, 1980, 19, 121-134.

Rhode, R. B., \& McCAll, F. H. Introduction to photography. New York: Macmillan, 1971.

Ross, B. H., \& Landauer, T. K. Memory for at least one of two items: Test and failure of several theories of spacing effects. Journal of Verbal Learning and Verbal Behavior, 1978, 17, 669-680.

RотнкорF, E. Z. Learning from written instructive materials: An exploration of the control of inspection behavior by test-like events. American Educational Research Journal, 1966, 3, 241 249.

Rотнкорғ, E. Z. Structural text features and the control of processes in learning from written materials. In R. O. Freedle \& J. B. Carroll (Eds.), Language comprehension and the acquisition of knowledge. Washington, D.C: Winston, 1972.

Rothkopf, E. Z., \& Bisbicos, E. Selective facilitative effects of interspersed questions on language from written material. Journal of Educational Psychology, 1967, 58, 56-61.

Rumelhart, D. E. Notes on a schema for stories. In D. G. Bobrow \& A. M. Collins (Eds.), Representation and understanding. New York: Academic Press, 1975.

Southwick, C. H. Ecology and the quality of our environment. New York: Von Nostrand Reinhold, 1972.

Stein, N. L., \& Glenv, C. G. Analysis of story comprehension in elementary school children. In R. Freedle (Ed.), Multidisciplinary perspectives in discourse comprehension. Hillsdale, N.J: Erlbaum, 1977.

Thorndyke, P. Cognitive structures in comprehension and memory of narrative discourse. Cognitive Psychology, 1977, 9 , 77-110.

Watts, G. H., \& Anderson, R. C. Effects of three types of inserted questions on learning from prose. Journal of Educa. tional Psychology, 1971, 62, 387-394.

\section{NOTE}

1. The pattern is the same if one includes only response times for correct answers.

\section{APPENDIX}

Below are three example main points, each with embellishments. Each set of facts is followed by a true-false question and a short-answer question.

\section{Example 1}

Main point. Temperature below or above the recommended standards can change the chemical activity of development.

Embellishments. Developing at temperatures higher than $80 \mathrm{deg}$ is inadvisable because of the possibility of damaging the emulsion layer of film.

To develop at below $60 \mathrm{deg}$ is inadvisable because film developers do not function properly.

Laboratory thermometers must be accurate and checked regularly with a second thermometer.

Truefalse question. Temperatures below recommended standards will change the chemical activity of development, but temperatures above the standard are not as harmful.

Short-answer question. What can change the chemical activity of development?

\section{Example 2}

Main point. Agitation keeps the solutions uniform, so that streaks on the negative caused by excess solution do not occur.

Embellishments. Agitation should begin the moment the film is placed in the developer and continue for the first $5 \mathrm{sec}$ of the development period.

Agitation should be used for about 5 of every $30 \mathrm{sec}$ throughout the development process.

Extreme agitation gives graininess to the image.

True-false question. Agitation results in solutions leaving streaks on the negatives.

Short-answer question. What keeps solutions uniform, thereby avoiding streaks on the negatives?

\section{Example 3}

Main point. Development of sheet film involves placing each piece of film onto individual hangers which are lowered into the tank.

Embellishments. Hangers should strike the edge of the tank to knock off air bubbles.

Agitation should be produced by lifting the hangers up and down.

All the hangers should be lifted together to avoid having the corner of one scratch neighboring film.

True-false question. Sheet film can be developed if each piece of film is hung on separate hangers and lowered into a tank.

Short-answer question. What kind of film is hung on individual hangers and then lowered into the tank? 